\title{
BBLR, PEMBERIAN ASI EKSKLUSIF, PENDAPATAN KELUARGA, DAN PENYAKIT INFEKSI BERHUBUNGAN DENGAN KEJADIAN STUNTING
}

\author{
Djuhadiah Saadong, Suriani B, Nurjaya, Subriah ${ }^{\bowtie}$ \\ Jurusan Kebidanan Poltekkes Kemenkes Makassar
}

\begin{tabular}{l} 
ARTICLE INFO \\
Article history \\
Submitted : 2021-01-12 \\
Revised : 2021-10-25 \\
Accepted : 2021-11-27 \\
\hline Keywords: \\
Exclusive breastfeeding \\
Low Birth Weight \\
Family income \\
Infectious diseases \\
Stunting
\end{tabular}

\section{Kata Kunci:}

ASI eksklusif

$B B L R$

Pendapatan keluarga

Penyakit infeksi

Stunting

\begin{abstract}
Stunting is a nutritional problem that hinders the growth process of toddlers. Toddler stunting has a negative impact that will last in the next life. According to UNICEF (2011), the nutritional status of children can be directly affected by factors, namely gender and low birth weight. Indirect factors, namely health status, infectious diseases/ Acute Respiratory Infections (ARI), diarrhea with low family income, parenting patterns, and not exclusive breastfeeding. The aim of the study was to investigate the relationship between low birth weight, exclusive breastfeeding, family income, and infectious diseases with the incidence of stunting in toddlers aged 24-59 months in the Mangasa Health Center Work Area in 2020. This was a case control study involving a total of 30 stunted and non-stunded children in each. The independent variables were low birth weight breastfeeding exclusive, family income, and infectious diseases, while the dependent variable is stunting. The study results show that children with low birth weight were like to have stunting 5.7 times than normal birth weight $(p=0.007)$. Similarly, children with formula and mixed feeding were likely to have stunting 5 times $(p=0.015)$ than exclusively breastfed children. Poor family income and the presence of infectious disease were also contributed to stunting $(\mathrm{OR}=7 ; \mathrm{p}=0.025, \mathrm{OR}=5.7, \mathrm{p}=$ 0.007 , respectively). In conclusion, the family income variable is the variable that has the most incidence of stunting among children aged $24-59$ months.

Stunting merupakan masalah gizi yang menghambat proses tumbuh kembang balita. Stunting pada balita memiliki dampak negatif yang akan bertahan di kehidupan selanjutnya. Status gizi anak secara langsung dapat dipengaruhi oleh beberapa faktor y aitu jenis kelamin dan berat badan lahir rendah. Faktor tidak langsung yaitu status kesehatan, penyakit menular/Infeksi Saluran Pernafasan Akut (ISPA), diare dengan pendapatan keluarga rendah, pola asuh, dan pemberian ASI yang tidak eksklusif. Penelitian ini bertujuan untuk mengetahui hubungan antara berat badan lahir rendah, ASI eksklusif, pendapatan keluarga, dan penyakit menular dengan kejadian stunting pada balita usia 24 - 59 bulan di Wilayah Kerja Puskesmas Mangasa Tahun 2020. Penelitian ini merupakan case control y ang melibatkan masing-masing 30 anak stunting dan non-stunting. Variabel bebasny a adalah BBLR, pendapatan keluarga, dan penyakit menular, sedangkan variabel terikatnya adalah stunting. Hasil penelitian menunjukkan bahwa anak dengan berat badan lahir rendah cenderung mengalami stunting 5,7 kali dibandingkan dengan berat badan lahir normal $(\mathrm{p}=0,007)$. Demikian pula anak dengan susu formula dan makanan campuran cenderung mengalami stunting 5 kali $(\mathrm{p}=0,015)$ dibandingkan anak y ang diberi ASI eksklusif. Pendapatan keluarga miskin dan adanya penyakit menular juga berkontribusi terhadap stunting $(\mathrm{OR}=7 ; \mathrm{p}=0,025, \mathrm{OR}=5,7, \mathrm{p}=$ 0,007 , masing-masing). Kesimpulannya, variabel pendapatan keluarga merupakan variabel y ang memiliki kejadian stunting terbany ak pada anak usia $24-59$ bulan.
\end{abstract}

Corresponding Author:

Subriah

Jurusan Kebidanan Poltekkes Kemenkes Makassar

Telp. 081221433225

Email: subriah@gmail.com

\section{PENDAHULUAN}

Stunting adalah masalah gizi utama yang masih banyak terjadi di Indonesia. Stunting sangat berdampak pada kehidupan sosial ekonomi masyarakat karena sangat berhubungan dengan pertumbuhan dan perkembangan kemampuan anak. Masalah gizi pada balita stunting akan menghambat proses tumbuh kembangnya yang akan berdampak pada kehidupan selanjutnya. Dalam sebuah studi menunjukkan bahwa balita stunting berpengaruh pada prestasi pendidikan yang 
tidak baik dan berpendapatan rendah sebagai orang dewasa. Balita stunting dihadapkan pada kemungkinan yang lebih besar untuk tumbuh menjadi versi dewasa yang kurang pendidikan, ekonomi kurang, kesehatan yang buruk dan rentan terhadap penyakit tidak menular (UNICEF, 2020). Global Nutrition Report tahun 2020 menunjukkan Indonesia telah membuat beberapa kemajuan dalam mencapai target stunting kan tetapi 30,8\% anak di bawah usia 5 tahun masih terkena dampaknya (Global Nutrition Report, 2020).

Prevalensi stunting di Indonesia menempati peringkat 115 dari 151 negara di dunia (KEMENKO PMK, 2021). Data Riset Kesehatan Dasar (Riskesdas) tahun 2020 menunjukkan prevalensi stunting dalam lingkup nasional sebesar $24,1 \%$.

Berdasarkan pemantauan status gizi tahun 2018, Sulawesi Selatan berada pada peringkat 13 dengan kecenderungan prevalensi balita stunting tertinggi dari 33 provinsi di Indonesia dengan presentasi 40 persen. Stunting adalah pertumbuhan anak gagal akibat kekurangan gizi secara berulang dalam waktu lama. Tingginya balita stunting Sulawesi Selatan lebih tinggi dari angka nasional pada tahun yang sama yakni 37,2 persen (TNP2K, 2017).

Survei pendahuluan yang telah dilakukan di Puskesmas Mangasa menunjukkan persentase balita stunting di wilayah ini adalah 104 balita. Balita dengan kekurangan gizi dan stunting berpotensi menghasilkan generasi bangsa dengan produktivitas rendah dan kemampuan bersaing rendah. Selain itu, kemampuan motorik rendah dan perkembangan fisik yang tidak optimal serta anak mudah menjadi sakit juga termasuk dalam potensi yang akan timbul yang disebabkan oleh stunting. Masalah gizi buruk tambahnya, bukan hanya karena faktor ekonomi, tetapi juga terkait budaya, dan beberapa penyakit infeksi.

Berdasarkan uraian tersebut peneliti tertarik untuk melakukan penelitian lebih lanjut tentang "Faktor Risiko Kejadian Stunting pada Anak Balita Usia 24 - 59 Bulan di Wilayah Kerja Puskesmas Mangasa Tahun 2020".

\section{METODE PENELITIAN}

\section{Jenis Penelitian}

Penelitian ini merupakan penelitian kuantitatif, dengan menggunakan desain case control.
Lokasi dan Waktu Penelitian

Penelitian ini dilakukan di Wilayah Kerja Puskesmas Mangasa mulai Bulan Maret sampai September 2020.

\section{Populasi dan Sampel}

Populasi dalam penelitian ini adalah seluruh anak balita di Wilayah Kerja Puskesmas Mangasa yang berumur 24 - 59 bulan. Pengambilan sampel menggunakan metode purposive sampling dengan jumlah sampel sebanyak 1:1 yaitu 30 sampel sebagai kasus dan 30 sampel sebagai kontrol sehingga jumlah sampel digunakan adalah 60 .

\section{Pengumpulan Data}

Jenis data dalam penelitian ini menggunakan data primer yaitu pengukuran tinggi badan dan antropometri, dan data sekunder yaitu berat badan lahir, pemberian ASI eksklusif, pendapatan keluarga serta penyakit infeksi berisiko. Adapun teknik pengumpulan data yang digunakan adalah dengan wawancara dan observasi data responden yang ada di Puskesmas Mangasa.

\section{Pengolahan dan Analisis Data}

Analisis hubungan dalam penelitian ini menggunakan perhitungan Odds Ratio yang dilakukan dengan menggunakan tabulasi silang antar variabel. Diketahui nilai OR dimungkinkan untuk memprediksi hubungan dari fakta yang diteliti terhadap kejadian stunting.

\section{HASIL PENELITIAN}

Karakteristik dalam penelitian ini yaitu berat badan lahir rendah (BBLR), ASI eksklusif, tingkat pendapatan keluarga, dan penyakit infeksi responden. Distribusi berdasarkan kejadian stunting, anak balita usia 24 - 59 bulan yang mengalami stunting sebanyak 30 anak $(50 \%)$ dan yang tidak mengalami stunting sebanyak 30 anak (50\%). Hasil penelitian menunjukkan bahwa distribusi responden berdasarkan berat badan lahir rendah, anak balita usia 24 - 59 bulan yang mengalami BBLR sebanyak 21 anak $(35,0 \%)$ dan yang tidak mengalami BBLR sebanyak 39 anak $(65,0 \%)$.

Berdasarkan distribusi pemberian ASI eksklusif, anak balita usia 24 - 59 bulan yang tidak mendapat ASI eksklusif sebanyak 20 anak $(33,3 \%)$ dan yang mendapat ASI eksklusif 
sebanyak 40 anak (66,7\%). Distribusi berdasarkan pendapatan keluarga, dimana pendapatan keluarga dalam kategori rendah sebanyak 12 keluarga $(20,0 \%)$ dan dalam kategori tinggi sebanyak 48 keluarga $(80,0 \%)$.
Distribusi berdasarkan penyakit infeksi, anak balita usia 24-59 bulan yang memiliki penyakit infeksi sebanyak 39 anak $(65,0 \%)$ dan yang tidak mempunyai penyakit infeksi sebanyak 21 $\operatorname{anak}(35,0 \%)$.

Tabel 1. Karakteristik Partisipan berdasarkan Variabel yang Diteliti di Wilayah Kerja Puskesmas Mangasa Kota Makassar

\begin{tabular}{lcc}
\hline \multicolumn{1}{c}{ Karakteristik } & n & \% \\
\hline Kejadian Stunting & 30 & 50 \\
$\quad$ Stunting & 30 & 50 \\
$\quad$ Normal & 60 & 100.0 \\
$\quad$ Total & & \\
Berat Badan Lahir Rendah & 21 & 35,0 \\
$\quad$ BBLR & 39 & 65,0 \\
Tidak BBLR & 60 & 100.0 \\
$\quad$ Total & & \\
Pemberian ASI Eksklusif & 20 & 33,3 \\
Tidak ASI Eksklusif & 40 & 66,7 \\
$\quad$ ASI Eksklusif & 60 & 100.0 \\
Total & & \\
Pendapatan Keluarga & 12 & 20,0 \\
$\quad$ Rendah & 48 & 80,0 \\
Tinggi & 60 & 100.0 \\
Total & & \\
Penyakit Infeksi & 39 & 65,0 \\
Ya & 21 & 35,0 \\
Tidak & 60 & 100.0 \\
Total & & \\
\hline
\end{tabular}

Sumber: Data Primer, 2020

Untuk mengetahui faktor yang paling berpengaruh dengan kejadian stunting maka dilakukan pengeluaran variabel yang memiliki $p$ value $<0,05$ dan nilai OR paling besar. Pada variabel BBLR, dari hasil uji kemaknaan nilai $p=0,007$, hasil probabilitas lebih kecil dari taraf signifikan 5\% $\quad(0,007<0,05) \quad$ artinya ada hubungan berat badan lahir rendah (BBLR) dengan kejadian stunting pada balita usia 24 59 bulan di Wilayah Kerja Puskesmas Mangasa Kota Makassar tahun 2020. Kemudian didapatkan nilai Odds Ratio $(\mathrm{OR})=5,71(95 \%$ $\mathrm{CI}=1,72-18,94)$, artinya balita yang memiliki berat badan lahir rendah 6 kali lipat memiliki risiko terjadinya stunting dibandingkan dengan balita dengan berat badan lahir normal. Dapat disimpulkan nilai $\mathrm{OR}=>1$ berarti berat badan lahir rendah merupakan faktor risiko terjadinya stunting pada balita usia 24 - 59 bulan di
Wilayah Kerja Puskesmas Mangasa Kota Makassar tahun 2020.

ASI eksklusif, dari hasil uji kemaknaan nilai $p=0,015$, hasil probabilitas lebih kecil dari taraf signifikan $5 \% \quad(0,015<0,05)$ artinya ada hubungan pemberian ASI eksklusif dengan kejadian stunting pada balita usia 24-59 bulan di Wilayah Kerja Puskesmas Mangasa Kota Makassar tahun 2020. Kemudian didapatkan nilai Odds Ratio $(\mathrm{OR})=5,000(95 \% \mathrm{CI}=1,51-$ 16,56), artinya balita yang tidak mendapatkan ASI eksklusif 5 kali lipat memiliki risiko terjadinya stunting dibandingkan dengan balita yang ASI eksklusif. Dapat disimpulkan nilai $\mathrm{OR}=>1$ berarti ASI eksklusif merupakan faktor risiko terjadinya stunting pada balita usia $24-$ 59 bulan di Wilayah Kerja Puskesmas Mangasa Kota Makassar tahun 2020. 
Pada variabel pendapatan keluarga, dari hasil uji kemaknaan nilai $p=0,025$, hasil probabilitas lebih kecil dari taraf signifikan 5\% $(0,025<0,05)$ artinya ada hubungan pendapatan keluarga dengan kejadian stunting pada balita usia 24 - 59 bulan di Wilayah Kerja Puskesmas Mangasa Kota Makassar tahun 2020. Kemudian didapatkan nilai Odds Ratio $(\mathrm{OR})=7,000(95 \%$ $\mathrm{CI}=1,381$ - 35,478), artinya balita yang pendapatan keluarganya dalam kategori rendah 7 kali lipat memiliki risiko terjadinya stunting dibandingkan dengan yang pendapatan keluarganya dalam kategori tinggi. Dapat disimpulkan nilai $\mathrm{OR}=>1$ berarti pendapatan keluarga merupakan faktor risiko terjadinya stunting pada balita usia $24-59$ bulan di Wilayah Kerja Puskesmas Mangasa Kota Makassar tahun 2020.
Penyakit infeksi, dari hasil uji kemaknaan nilai $p=0,007$, hasil probabilitas lebih kecil dari taraf signifikan $5 \%$ $(0,007<0,05)$ artinya ada hubungan penyakit infeksi dengan kejadian stunting pada balita usia 24 - 59 bulan di Wilayah Kerja Puskesmas Mangasa Kota Makassar tahun 2020. Kemudian didapatkan nilai Odds Ratio $(\mathrm{OR})=5,714(95 \%$ $\mathrm{CI}=1,724-18,944)$, artinya balita yang memiliki penyakit infeksi 6 kali lipat memiliki risiko terjadinya stunting dibandingkan dengan balita yang tidak memiliki penyakit infeksi.

Dapat disimpulkan nilai $\mathrm{OR}=>1$ berarti penyakit infeksi merupakan faktor risiko terjadinya stunting pada balita usia $24-59$ bulan di Wilayah Kerja Puskesmas Mangasa Kota Makassar tahun 2020.

Tabel 2. Hubungan Be rat Badan Lahir, Pemberian ASI Eksklusif, Pendapatan Keluarga, dan Penyakit Infeksi dengan Kejadian Stunting pada Balita Usia 24 - 59 Bulan di Wilayah Kerja Puskesmas Mangasa Kota Makassar

\begin{tabular}{|c|c|c|c|c|c|c|c|c|}
\hline \multirow{3}{*}{ Variabel Penelitian } & \multicolumn{4}{|c|}{ Kejadian Stunting } & \multirow{2}{*}{\multicolumn{2}{|c|}{ Total }} & \multirow{3}{*}{ Nilai $p$} & \multirow{3}{*}{ Nilai OR } \\
\hline & \multicolumn{2}{|c|}{ Stunting } & \multicolumn{2}{|c|}{ Normal } & & & & \\
\hline & $\mathbf{N}$ & $\%$ & $\mathbf{N}$ & $\%$ & $\mathbf{N}$ & $\%$ & & \\
\hline \multicolumn{9}{|l|}{ Be rat B adan Lahir } \\
\hline BBLR & 16 & 26,7 & 5 & 8,3 & 21 & 35,0 & \multirow{3}{*}{0,007} & \multirow{3}{*}{$\begin{array}{c}5,71 \\
\text { CI }(1,72- \\
18,94)\end{array}$} \\
\hline Tidak BBLR & 14 & 23,3 & 25 & 41,7 & 39 & 65,0 & & \\
\hline Total & 30 & 50 & 30 & 50 & 60 & 100,0 & & \\
\hline \multicolumn{9}{|l|}{ Pemberian ASI Eksklusif } \\
\hline Tidak ASI Eksklusif & 15 & 25,0 & 5 & 8,3 & 20 & 33,3 & \multirow{3}{*}{0,015} & \multirow{3}{*}{$\begin{array}{c}5,000 \\
\text { CI }(1,51- \\
16,56)\end{array}$} \\
\hline ASI Eksklusif & 15 & 25,0 & 25 & 41,7 & 40 & 66,7 & & \\
\hline Total & 30 & $\mathbf{5 0 , 0}$ & 28 & $\mathbf{5 0 , 0}$ & 60 & 100,0 & & \\
\hline \multicolumn{9}{|l|}{ Pendapatan Keluarga } \\
\hline Rendah & 10 & 16,7 & 2 & 3,3 & 12 & 20,0 & \multirow{3}{*}{0,025} & 7,000 \\
\hline Tinggi & 20 & 33,3 & 28 & 46,7 & 48 & 80,0 & & $\begin{array}{c}\text { CI } \\
(1381-\end{array}$ \\
\hline Total & 30 & $\mathbf{5 0 , 0}$ & 30 & $\mathbf{5 0 , 0}$ & 60 & 100,0 & & $35,478)$ \\
\hline \multicolumn{9}{|l|}{ Penyakit Infeksi } \\
\hline $\mathrm{Ya}$ & 25 & 41,7 & 14 & 23,3 & 39 & 65,0 & \multirow{3}{*}{0,007} & \multirow{3}{*}{$\begin{array}{c}5,714 \\
\text { CI } \\
(1,724- \\
18,944)\end{array}$} \\
\hline Tidak & 5 & 8,3 & 16 & 26,7 & 21 & 35,0 & & \\
\hline Total & 30 & 50,0 & 30 & $\mathbf{5 0 , 0}$ & 60 & 100,0 & & \\
\hline
\end{tabular}

Sumber: Data Primer, 2020 
Setelah dilakukan pengeluaran variabel yang memiliki $p$ value $<0,05$ dan nilai $\mathrm{OR}$ paling besar maka disimpulkan bahwa variabel pendapatan keluarga merupakan variabel yang memiliki hubungan paling dominan dengan kejadian stunting pada anak balita usia $24-59$ bulan di Wilayah Kerja Puskesmas Mangasa Kota Makassar tahun 2020.

Tabel 3. Seleksi Kandidat Analis is Multivariat berdasarkan Hasil Analisis Bivariat

\begin{tabular}{lccc}
\hline \multicolumn{1}{c}{ Variabel } & $\boldsymbol{p}$ & OR & $\mathbf{9 5 \%}$ CI \\
\hline BBLR & 0,007 & 5,71 & $(1,72-18,94)$ \\
ASI Eksklusif & 0,015 & 5,000 & $(1,51-16,56)$ \\
Pendapatan Keluarga & 0,025 & 7,000 & $(1,381-35,478)$ \\
Penyakit Infeksi & 0,007 & 5,714 & $(1,724-18,944)$ \\
\hline
\end{tabular}

Sumber: Data Primer, 2020

\section{PEMBAHASAN}

\section{Hubungan berat badan lahir rendah dengan kejadian stunting}

Dari hasil uji menunjukkan ada hubungan berat badan lahir rendah (BBLR) dengan kejadian stunting pada balita usia 24 59 bulan di Wilayah Kerja Puskesmas Mangasa Kota Makassar tahun 2020. Dapat disimpulkan bahwa berat badan lahir rendah merupakan faktor risiko terjadinya stunting pada balita usia 24 - 59 bulan di Wilayah Kerja Puskesmas Mangasa Kota Makassar tahun 2020.

Hal ini sejalan dengan hasil penelitian (Nainggolan \& Sitompul, 2019) di Kota Banda Aceh, bahwa faktor yang berpengaruh terhadap stunting pada balita adalah BBLR. Anak yang terlahir dengan BBLR lebih berpotensi stunting dibandingkan anak yang terlahir dengan berat normal.

Hal ini sesuai dengan hasil penelitian yang dilakukan oleh (Sihombing, 2019) yang menyatakan bahwa berat badan lahir rendah memiliki hubungan dengan kejadian stunting yang disebabkan oleh keadaan gizi ibu yang kurang selama kehamilan sehingga menyebabkan intra uterine growth retardation, dan ketika lahir dimanifestasikan dengan rendahnya berat badan lahir.

Berat badan lahir merupakan salah satu indikator kesehatan pada bayi yang baru lahir. Berat badan lahir merupakan parameter yang sering dipakai untuk menggambarkan pertumbuhan janin pada masa kehamilan. Bayi dengan berat badan lahir rendah akan lebih rentan terhadap pengaruh lingkungan yang kurang baik di masa mendatang. Bayi yang lahir dengan BBLR lebih berisiko untuk tumbuh stunting dibandingkan dengan yang lahir normal. Balita dengan riwayat BBLR ditambah dengan pola makan yang tidak benar dapat membuat pemenuhan gizi belum tercukupi.

\section{Hubungan pemberian ASI eksklusif dengan kejadian stunting}

Dari hasil menunjukkan bahwa ada hubungan pemberian ASI eksklusif dengan kejadian stunting pada balita usia $24-59$ bulan di Wilayah Kerja Puskesmas Mangasa Kota Makassar tahun 2020. Dapat disimpulkan bahwa ASI eksklusif merupakan faktor risiko terjadinya stunting pada balita usia 24 - 59 bulan di Wilayah Kerja Puskesmas Mangasa Kota Makassar tahun 2020.

Sejalan dengan penelitian (Ni'mah \& Nadhiroh, 2021) menunjukkan bahwa balita yang tidak mendapatkan ASI eksklusif selama 6 bulan pertama lebih tinggi pada kelompok balita stunting $(88,2 \%)$ dibandingkan dengan kelompok balita normal (61,8\%). Hasil Uji $C h i$ Square menunjukkan bahwa terdapat hubungan antara pemberian ASI eksklusif dengan kejadian stunting dengan OR sebesar 4,643.

Hasil penelitian ini juga sejalan dengan (Agustina \& Hamisah, 2019), pemberian ASI eksklusif dengan kejadian stunting pada balita 24 - 59 bulan. Dimana diperoleh $p$ value $=$ $0,003(0,003<0,05)$. Maka disimpulkan bahwa terdapat hubungan pemberian ASI eksklusif dengan kejadian stunting pada balita 24-59 bulan. ASI merupakan asupan gizi yang sesuai dengan kebutuhan akan membantu pertumbuhan dan perkembangan anak.

ASI memiliki banyak manfaat, misalnya meningkatkan imunitas anak terhadap penyakit, infeksi telinga, menurunkan frekuensi 
diare, konstipasi kronis dan lain sebagainya. Kurangnya pemberian ASI dan pemberian MPASI yang terlalu dini dapat meningkatkan risiko terjadinya stunting terutama pada awal kehidupan. Besarnya pengaruh ASI eksklusif terhadap status gizi anak membuat WHO merekomendasikan agar menerapkan intervensi peningkatan pemberian ASI selama 6 bulan pertama salah satu cara untuk mencegah stunting menurut rekomendasi WHO dan UNICEF adalah pemberian ASI eksklusif sampai bayi berumur enam bulan. ASI eksklusif artinya bayi tidak mendapat asupan lainnya selain ASI (Tanoto Foundation, 2019).

\section{Hubungan pendapatan keluarga dengan kejadian stunting}

Dari hasil uji menunjukkan adanya hubungan pendapatan keluarga dengan kejadian stunting pada balita usia $24-59$ bulan di Wilayah Kerja Puskesmas Mangasa Kota Makassar tahun 2020. Dapat disimpulkan bahwa pendapatan keluarga merupakan faktor risiko terjadinya stunting pada balita usia $24-$ 59 bulan di Wilayah Kerja Puskesmas Mangasa Kota Makassar tahun 2020.

Sejalan dengan penelitian (Ni'mah \& Nadhiroh, 2021), pendapatan keluarga merupakan faktor yang berhubungan dengan kejadian stunting pada balita $(p=0,044)$ dengan OR sebesar 3,250. Pada hasil analisis menunjukkan terdapat hubungan yang signifikan antara pendapatan keluarga terhadap kejadian stunting pada anak balita baik yang berada di daerah pedesaan maupun di perkotaan. Sama halnya dengan penelitian lain yang menyatakan bahwa status ekonomi keluarga yang rendah di Maluku Utara berhubungan signifikan dengan kejadian stunting pada balita usia $0-59$ bulan. Apabila ditinjau dari karakteristik pendapatan keluarga bahwa akar masalah dari dampak pertumbuhan bayi dan berbagai masalah gizi lainnya salah satunya disebabkan karena krisis ekonomi.

Sependapat dengan penelitian (Ni'mah \& Nadhiroh, 2021), keluarga pada kelompok balita normal cenderung berpenghasilan cukup (50\%) dibandingkan dengan keluarga balita stunting $(23,5 \%)$. Hasil analisis Chi Square menunjukkan bahwa pendapatan keluarga merupakan faktor yang berhubungan dengan kejadian stunting pada balita $(p=0,044)$ dengan OR sebesar 3,250. Keluarga dengan status ekonomi baik akan dapat memeroleh pelayanan umum yang lebih baik seperti pendidikan, pelayanan kesehatan, akses jalan, dan lainnya sehingga dapat memengaruhi status gizi anak. Selain itu, daya beli keluarga akan semakin meningkat sehingga akses keluarga terhadap pangan akan menjadi lebih baik.

\section{Hubungan penyakit infeksi dengan kejadian stunting}

Dari hasil uji menunjukkan ada hubungan penyakit infeksi dengan kejadian stunting pada balita usia $24-59$ bulan di Wilayah Kerja Puskesmas Mangasa Kota Makassar tahun 2020. Dapat disimpulkan bahwa penyakit infeksi merupakan faktor risiko terjadinya stunting pada balita usia $24-59$ bulan di Wilayah Kerja Puskesmas Mangasa Kota Makassar tahun 2020.

Sejalan dengan penelitian yang dilakukan oleh (Aridiyah et al., 2015), terdapat hubungan antara riwayat penyakit infeksi dengan kejadian stunting pada anak balita baik yang berada di pedesaan maupun yang berada di perkotaan. Penelitian yang dilakukan di Karangasem yang menunjukkan bahwa penyakit infeksi dapat mengganggu pertumbuhan yang juga mempengaruhi status gizi anak balita.

Terdapat interaksi bolak-balik antara status gizi dengan penyakit infeksi. Malnutrisi dapat meningkatkan risiko infeksi. Apabila kondisi ini terjadi dalam waktu lama dan tidak segera diatasi maka dapat menurunkan intake makanan dan mengganggu absorpsi zat gizi, sehingga dapat meningkatkan risiko terjadinya stunting pada anak balita.

Penelitian ini juga sejalan dengan (Desyanti \& Nindya, 2017), menyatakan ada hubungan antara riwayat penyakit diare dengan kejadian stunting dimana nilai $p=0,025$ dan nilai OR sebesar 3,619 yang artinya balita yang sering mengalami diare berisiko mengalami stunting 4 kali lebih besar daripada balita yang jarang mengalami diare di Wilayah Kerja Puskesmas Simolawang.

\section{KESIMPULAN DAN SARAN}

Ada hubungan Berat Badan Lahir, pemberian ASI eksklusif, pendapatan keluarga, penyakit infeksi dengan kejadian stunting pada balita usia 24 - 59 bulan di Wilayah Kerja Puskesmas Mangasa Makassar. Dengan adanya penelitian ini diharapkan kepada seluruh pihak yang terlibat seperti fasilitas kesehatan, orang 
tua, institusi maupun peneliti selanjutnya untuk saling berkoordinasi untuk mencegah adanya kejadian stunting dengan memperhatikan beberapa aspek yang dapat menyebabkan kejadian stunting

\section{DAFTAR PUSTAKA}

Agustina, \& Hamisah, I. (2019). Hubungan Pemberian Asi Ekslusif, Berat Bayi Lahir Dan Pola Asuh Dengan Kejadian Stunting Di Wilayah Kerja Puskesmas Reubee Kabupaten Pidie. Journal of Healthcare Technology and Medicine., 5(2), 162-170. https:/doi.org/ 10.33143/jhtm.v5i2.397.

Aridiyah, F. O., Rohmawati, N., \& Ririanty, M. (2015). Faktor-faktor yang Mempengaruhi Kejadian Stunting pada Anak Balita di Wilayah Pedesaan dan Perkotaan (The Factors Affecting Stunting on Toddlers in Rural and Urban Areas). E-Jurnal Pustaka Kesehatan, 3(1), 163-170. https://jurnal.unej.ac.id/ index.php/JPK/article/view/2520.

Desyanti, C., \& Nindya, T. S. (2017). Hubungan Riwayat Penyakit Diare dan Praktik Higiene dengan Kejadian Stunting pada Balita Usia 24-59 Bulan di Wilayah Kerja Puskesmas Simolawang, Surabaya. Amerta Nutrition, 1(3), 243. https://doi.org/10.20473/amnt.v1i3.6251.

Global Nutrition Report. (2020). Country Nutrition Profiles. https:// globalnutritionreport.org/resources/nutriti on-profiles/.

KEMENKO PMK. (2021). Menko PMK Beberkan Kunci Atasi Gizi Buruk dan
Stunting. https://www.kemenkopmk.go. id/menko-pmk-beberkan-kunci- atasigizi-buruk-dan-stunting.

Nainggolan, B. G., \& Sitompul, M. (2019). Hubungan Berat Badan Lahir Rendah (BBLR) dengan Kejadian Stunting Pada Anak Usia 1-3 Tahun. Nutrix Journal, 3(1), 36. https://doi.org/10.37771/nj. vol3.iss1.390.

Ni'mah, K., \& Nadhiroh, S. R. (2021). Faktor yang Berhubungan dengan Kejadian Stunting pada Balita. Media Gizi Indonesi, 10(1), 13-19. https//doi.org/ 10.20473/mgi.v10i1.13-19.

Sihombing, F. (2019). Hubungan BBLR dan ASI Ekslusif dengan Kejadian Stunting di Puskesmas Medan Tuntungan. Jurnal Amenorea Laktasi, 4(1), 1-8. https://journal.universitasaudi.ac.id/index .php/JAL/article/view/6.

Tanoto Foundation. (2019). Cegah Stunting dengan ASI Ekslusif. https://www. tanotofoundation.org/id/news/ cegahstunting-dengan-asi-ekslusif/.

TNP2K. (2017). 100 Kabupaten/Kota Prioritas untuk Intervensi Anak Kerdil (Stunting) (Cetakan Pe). http:/www.tnp2k. go.id/downloads/100- kabupatenkotaprioritas-untuk-intervensi-anak-kerdilstunting-volume- 2 .

UNICEF. (2020). Mengatasi Beban Ganda Malnutrisi di Indonesia. UNICEF (Online). https://www.unicef.org/ indonesia/id/gizi. 